\title{
Discussion on Increasing College Teachers' Willingness to Adopt Web-based Learning in Teaching
}

\author{
Chun-An Chen \\ Assistant Professor \\ Department of International Business, Chung Hua University \\ 707, Sec. 2, WuFu Rd., HsinChu, Taiwan \\ Tel: 886-3-5186761Ｅ-mail: cachen@chu.edu.tw
}

Received: June 9, 2012

Accepted: June 25, 2012

Online Published: July 3, 2012

doi:10.5430/bmr.v1n3p1

URL: http://dx.doi.org/10.5430/bmr.v1n3p1

\begin{abstract}
Web-based learning is one of the most common learning channels and useful components for students and teachers in colleges and universities. Web-based learning is gradually becoming a trend because it offers learners more flexibility. Therefore, this study aims to investigate how to increase the college teachers' willingness to adopt web-based learning in their teaching. It applies the DEMATEL method to analyze the degree of influence among the criteria. It also uses the MMDE to solve the threshold value problem. The study results reveal that the "web-based learning is helpful" criterion has obtained the highest value. In other words, if teachers realized the value of web-based learning to students, it might increase their willingness to use it.
\end{abstract}

Keywords: Web-based learning, Willingness, DEMATEL, MMDE

\section{Introduction}

The rapid development and prevalence of the web, the images, sounds, and videos that are integrated in the web make the web more interesting and popular. Web-based learning is also one of the most common learning channels. Web-based learning enables education to take place anytime, anywhere (Hsu, Huang and Wang, 2004). Furthermore, it can facilitate face-to-face teaching in common classrooms and create separate virtual classrooms. This provides students with different choices and opportunities to get involved in a learning environment in today's information society. Students can experience more diversified learning styles with the help of web-based learning. Web-based learning is becoming the trend of the future. As Yang (2003) mentioned, the advantage of web-based learning is that teaching is free from restrictions. It can break the barriers of time and space, and allow information to be updated any time, which makes usage more convenient. Moreover, web-based learning makes education more flexible.

However, according to Shen (2007), only half of Taiwanese college teachers have adopted web-based learning. Moreover, $70 \%$ or $80 \%$ of them use a web-based learning just to store teaching outlines and materials. Fifty percent $(50 \%)$ of the teachers use it for collecting students' homework. This study aims to discuss how to create a positive attitude among college teachers towards web-based learning as well as how to further increase the teachers' willingness to adopt web-based learning.

DEMATEL (Decision-Making Trial and Evaluation Laboratory) is used mainly for analyzing problems and quantifying the degree of influence among the elements. This method was designed for problem solving, and it has been utilized in various studies (Tsai, Chou and Lai, 2010; Tsai, Hsu, Chen, Lin and Chen, 2010; Tsai and Hsu 2010; Tsai, Leu, Liu, Lin and Shaw, 2010; Chen, Lee and Yang, 2012; Chen, Lee and Wu, 2012; Chen, Lee, Lee and Yang, 2011). Based on previous studies, it also applied DEMATEL to analyze the degree of influence among the criteria and used the Maximum Mean De-Entropy Algorithm (MMDE) to solve the threshold value problem.

This study primarily aims to discuss how to increase college teachers' willingness to adopt web-based learning. Through literature review and sorting, it illustrates the definition and significance of all variables. 


\section{Literature Review}

\subsection{Teacher's perception}

With the constant progress of information technology, web-based learning has become a trend. In addition to the web-based learning and curriculum design, teachers' willingness to participate is more important to the success of web-based learning.

Personal accomplishment refers to the feeling of the individuals that they have the ability to deal with problems (Kuo, 1990). Having a sense of accomplishment has a great effect on satisfaction and persistence of job (Chang, Su and Chang, 2010). If teachers are highly encouraged and motivated, they would be more likely to use the web-based learning for teaching. Moreover, if teachers feel that teaching is accomplished, challenging, and meaningful, it can serve as a motivation to trigger teachers to use the web-based learning for teaching.

\subsection{School management measures}

Communication involves delivering thoughts to others while promoting mutual understanding in our daily life. Organizational communication can be is a dynamic process that depends on the requirements of a job, the organization members' utilization of the internal channels to contact each other, delivery and exchange of messages, consensus achieved to coordinate or satisfy a need thus achieve a goal set by that organization (Lee, 1999).

Performance evaluation system is often used to evaluate staffs' performance and to stimulate efficiency and promote organizational development (Fu and Wang, 2010). Performance evaluation system and leadership style are positively correlated to job attitudes (Yu, 2007). In other words, a good performance evaluation system and leadership style will have a positive effect on teachers' willingness to use the web-based learning for teaching.

Based on related studies showing the influence of the staff's willingness to work, this study applied the school management measures, which has the following criteria: "The school's respect of teachers' opinions", "The school's overall communication channels", and "The school's fair and rational performance evaluation system".

\subsection{Web-based learning system}

Hsu et al. (2004) mentioned that the Technology Acceptance Model provides different definitions of "Usefulness" and "Ease of use". "Usefulness" is the subjective rate of expecting to improve one's work performance through a certain system, while "Ease of use" is user's cognition regarding the degree of ease in using the system. "Usefulness" will directly affect the user's intention. Thus, this study applies "Usefulness" and "Ease of use," which were mentioned in the Technology Acceptance Model as the criteria for web-based learning system.

\subsection{Interaction with Learners}

In this era of information technology evolution, IT significantly influences our life, work, and learning. Discussion and communication between students can greatly improve remote education, which can further enhance learning and provide opportunities for exchanging ideas ( $\mathrm{Wu}$ and $\mathrm{Wu}, 2005)$. Web-based learning can provide teachers and students with a learning environment that is free from the restrictions of time, space, and location. Aside from transferring traditional teaching content to the web, web-based learning can also take advantage of various web and multi-media features, such as e-mails, online communication, or group discussion, among others, all of which strengthen the cohesion and interactivity of web-based learning (Chris and Lindsay, 1998).

\section{Methods}

This study uses the DEMATEL method, which is designed mainly for solving problems and quantifying the degree of relevance and influence intensity among all elements. Moreover, MMDE determines the threshold value, eliminating some elements with low degree of influence. The following is the introduction and steps for analyzing and utilizing DEMATEL.

\subsection{DEMATEL}

In 1971, Geneva Battelle Institute used the Decision Making Trial and Evaluation Laboratory (DEMATEL) to solve technological and human issues, such as race, hunger, environmental protection, and other problems. Later on, this method was applied to solve problems concerning decisions, that is, to clarify the essential features of the problems and adopt countermeasures. Tzeng used the fundamentals of this method to transform the attributes of the application and evaluation into a non-independent multi-criteria evaluation of problems (Huang and Tzeng, 2007; Liou, Tzeng and Chang, 2007; Tzeng, Chiang and Li, 2007). Over the years, a number of studies have used DEMATEL as a study method in a wide range of fields.

DEMATEL then determines the interdependent and constraining relations based on the specific features of the 
subjects. In this way, it reflects the essential features and the evolving trend of the system.

Calculation Steps of DEMATEL

Step 1: Generation of Direct-relation Matrix Model:

$Z_{\mathrm{ij}}$ represents the degree of influence of element $a_{i}$ to $a_{j}$, which then forms the direct influence matrix " $Z$ ".

$$
\begin{aligned}
& a_{1} \ldots a_{i} \ldots a_{n}
\end{aligned}
$$

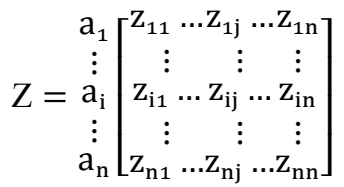

Step 2: Calculation of the Standardized Direct-relation Matrix

After standardizing the direct matrix obtained from Step 2, let $s=\min \left[1 / \max \sum_{j=1}^{n} z_{i j}, 1 / \max \sum_{i=1}^{n} z_{i j}\right]$, then the entire matrix element " $Z$ " is divided by " $s$ ", which leads to the equation $X=Z / s$, that is, the standardized direct-relation matrix " $X$ ".

Step 3: Calculating Matrix for Total Influence

A continuous decrease of the indirect effects of problems along the powers of matrix $X$, e.g. $X^{2}, X^{3}, \ldots, X^{\infty}$, guarantees convergent solutions to the matrix inversion similar to an absorbing Markov chain matrix. The total relation matrix $T$, is defined as $T=\lim _{q \rightarrow \infty}\left(X+X^{2}+\ldots+X^{q}\right)=X(I-X)^{-1}$, where $I$ is the $n \times n$ identity matrix.

Step 4: Calculating the Prominence and Relevance

Let $T_{i j}(i, j=1,2, \ldots, \mathrm{n})$ be the elements of $T$, then the sums of all columns and rows are $D_{i}$ and $R_{j}$, respectively.

$$
\begin{aligned}
D_{i} & =\sum_{i=1}^{n} \operatorname{Tij}(i=1,2, \ldots . ., n) \\
R_{j} & =\sum_{j=1}^{n} \operatorname{Tij}(j=1,2, \ldots . ., n)
\end{aligned}
$$

The $D_{i}$ shows the sum of influence directly exerted from element $T_{i}$ to the other elements. Then $R_{j}$ shows the sum of influence that element $T_{j}$ received from other elements. $(D+R)$ is called prominence, which indicates the element's degree of influence and being influenced. $(D-R)$ is called relation. If it is positive, the element tends to fall under the result category. If it is negative, the element tends to fall under the causal category.

\section{Step 5: Drawing the Cause-effect Diagram}

Set $(D+R)$ as the $\mathrm{X}$-axis and $(D-R)$ as the $\mathrm{Y}$-axis. The cause-effect diagram can show the complicated causal relation, which can be analyzed deeply and solved completely.

Step 6: Analysis Matrix for Total Influence

The $\mathrm{X}$-axes $(\mathrm{D}+\mathrm{R})$ indicates the sum of the criteria attribute that either influences other criteria or other criteria influence the initial attribute. The $\mathrm{Y}$-axis $(D-R)$ indicates the difference in the criteria attribute that influence other criteria or other criteria influence difference in the attribute.

\subsection{Maximum Mean De-Entropy Algorithm}

DEMATEL is mainly used to solve problems, quantify the degree of relevance, and influence the intensity among problem elements. When applying DEMATEL, one can graphically display the problem to be solved. The diagram can better clarify the problem, but obtaining the appropriate diagram and setting the threshold value can affect the problem analysis and judgment. In the past, experts determined the threshold. However, it is quite difficult to get a consensus on the threshold value. At times, a researcher would set the threshold value by him or herself. Therefore, obtaining the threshold value is different for each researcher (Li and Tzeng, 2009).

The steps of MMDE method are described as follows (Li and Tzeng, 2009):

Step 1: Transforming the $\mathrm{n} \times \mathrm{n}$ total relation matrix $\mathrm{T}$ into an ordered set $\mathrm{T},\left\{\mathrm{t}_{11}, \mathrm{t}_{12}, \ldots, \mathrm{t}_{21}, \mathrm{t}_{22}, \ldots, \mathrm{t}_{\mathrm{nn}}\right\}$, rearranging the order of elements in set $\mathrm{T}$ from large to small and transforming to a corresponding set of ordered triplets $\left(\mathrm{t}_{\mathrm{ij}}, \mathrm{x}_{\mathrm{i}}, \mathrm{x}_{\mathrm{j}}\right)$ denotes $\mathrm{T}^{*}$. Each element of set $\mathrm{T}, \mathrm{t}_{\mathrm{ij}}$, can also be seen as the ordered triplets $\left(\mathrm{t}_{\mathrm{i} j}, \mathrm{x}_{\mathrm{i}}, \mathrm{x}_{\mathrm{j}}\right)$ (influence value, dispatch-node, 
receive-node) denoting $\mathrm{T}^{*}$.

Step 2: Taking the second element as the dispatch-node from the ordered triplets of the set $\mathrm{T}^{*}$, then obtaining a new ordered dispatch-node set, $\mathrm{T}^{\mathrm{Di}}$.

Step 3: Taking the first $t$ elements of $\mathrm{T}^{\mathrm{Di}}$ as a new set $\mathrm{T}_{\mathrm{t}}^{\mathrm{Di}}$, assigning the probability of different elements, and then calculating the $\mathrm{H}^{\mathrm{D}}$ of the set $\mathrm{T}_{\mathrm{t}}^{\mathrm{Di}}, \mathrm{H}_{\mathrm{t}}^{\mathrm{Di}}$, we can calculate the mean de-entropy by Eq. $\mathrm{MDE}_{\mathrm{t}}^{\mathrm{Di}}=\mathrm{H}_{\mathrm{t}}^{\mathrm{Di}} / \mathrm{N}\left(\mathrm{T}_{t}^{\mathrm{Di}}\right)$

Step 4: In $C\left(T_{t}^{D i}\right)$ mean de-entropy values, choosing the maximum mean de-entropy and its corresponding $T_{t}^{D i}$. This dispatch-node set, with the maximum mean de-entropy, is denoted as $\mathrm{T}_{\max }$.

Step 5: Similar to Steps 2-4, an ordered receive-node set $\mathrm{T}^{\mathrm{Re}}$ and a maximum mean de-entropy receive-node set $\mathrm{T}_{\max }{ }^{R e}$ can be determined. The elements of $\mathrm{T}_{\max }{ }^{\mathrm{Re}}$ provide information that is easily influenced.

Step 6: Taking the first $u$ elements in $T^{*}$ as the subset, $T^{\text {Th }}$, which includes all elements of $T_{\max }$ in in the dispatch-node and all elements of $\mathrm{T}_{\max }{ }^{\mathrm{Re}}$ in the receive-node, the minimum influence value in $\mathrm{T}^{\mathrm{Th}}$ reflects the threshold value.

\subsection{Study Framework}

Based on the literature review, many scholars have discussed elements such as the teacher's perception, school management measures, web-based learning system, and teachers' interaction with learners. Thus, this study aims to discuss the correlation and the degree of influence among these elements. The framework and meaning of each criterion in this study is shown in Table 1.

\section{Results}

This study uses DEMATEL to conduct surveys among college teachers to find out the correlation among the criteria. The framework of this study includes four dimensions; namely, "teacher's perception", "the school management measures", "web-based learning system", and "the interaction with learners". All these consist of 11 criteria in total. The questionnaires are evaluated at four levels "0", "1", "2", "3", indicated as "No influence", "Low influence", "Medium influence", and "Intense influence", respectively. This study distributed DEMATEL expert questionnaires to the respondents, all of whom are teachers with over 5-year teaching experience. According to Teng (2002), 5 to 15 experts would be appropriate for group decision making. This study distributed 15 questionnaires in total.

All questionnaire results were sorted to obtain full-relation matrix of criteria, as shown in Table 2.

After summing up the rows and columns in Table 2, we can get the sum value of all columns (D) and rows (R) and then calculate the $\mathrm{D}+\mathrm{R}$ and $\mathrm{D}-\mathrm{R}$, as shown in Table 3 .

From Table 3, we can determine the interrelation among the 11 criteria. The total relation matrix includes direct and indirect influences, denoted as $\mathrm{D}, \mathrm{R}, \mathrm{D}+\mathrm{R}$, and $\mathrm{D}-\mathrm{R}$. D represents the factors showing direct and indirect influences on other elements. $\mathrm{R}$ represents the factors directly and indirectly influenced by other elements. $\mathrm{D}+\mathrm{R}$ represents the relation intensity among the criteria (prominence) or the degree of influence on others. D-R represents the standard intensity of the influence or the degree of being influenced (causal degree). A positive (D-R) indicates that this criterion influences others. On the contrary, a negative (D-R) indicates that it is influenced by others. Through the value data of $(D+R)$ and $(D-R)$ in Table 3, we set $(D+R)$ as the $X$-axis and $(D-R)$ as the $Y$-axis and draw the Causality Diagram of Criteria based on the value of these four dimensions, as shown in Figure 1.

This study included 11 criteria in total. In terms of $(D+R)$ degree of relevance, the top three items, namely "d1 = E-mail and group discussion", "a1 = Acquiring a sense of success from web-based learning", "c3 = Convenience", are highly important in the whole evaluation. In terms of (D-R) degree of influence, the top three items for the positive values, namely, "a3 = Web-based learning is helpful", "b1 = The school's respect for the opinions of teachers", "b2 = The school's overall communication channels", have the strongest influence on other criteria.

By combining (D+R) with (D-R), the following conclusions can be obtained. Although "a3 web-based learning is helpful" only has an average influence in terms of $(D+R)$ degree of relevance, it can obtain the highest value in terms of (D-R). This means that when teachers understand that web-based learning is helpful to students' learning, teachers' willingness to adopt web-based learning increases.

\section{Conclusions}

This study discusses mainly increasing teachers' willingness to adopt web-based learning. It also determines the interrelation of different criteria. These results were further analyzed to improve and increase teachers' willingness to use web-based learning. In the criteria analysis of (D-R) "a3: Web-based learning is helpful" had the highest value. In other words, when teachers apply web-based learning and realize its value to students, and when students interact with teachers through a web-based learning, the willingness of teachers to use web-based learning may increase. 
Improved content of web-based learning, such as online testing or discussions, can promote the use of web-based learning for both teachers and students. It can also increase teachers' willingness to adopt web-based learning. Further research could explore the reasons for teachers not using the web-based learning and make the study more complete. In short, teachers' understanding that web-based learning is helpful to students' learning will enhance the teachers' willingness to use the web-based learning. Therefore, schools or educational institutions can investigate the associated data to show that web-based learning is conducive to students. Emphasizing that web-based learning is helpful to students' learning can increase the efficiency of teaching, which can enhance teachers' willingness to use web-based learning and improve the utilization and quality of web-based learning.

\section{Limitations and Recommendations}

\subsection{Limitations}

The quantity of the questionnaire survey in this research is too limited. The result of this research will be more convincing if the samples of the questionnaire are more.

\subsection{Recommendations}

This study subjects are mainly teachers who have applied web-based learning in their teaching. The research will be more profound and complete if we can study and analyze the reasons why some teachers are not willing to use web-based learning in their teaching in the further study.

\section{References}

Chen, C.A., Lee, H.L. \& Wu, C.H. (2012). How Taiwan's Semiconductor Distributors Select Strategic Partners in China. Journal of Technology Management in China, 7(1), 36-49. http://dx.doi.org/10.1108/17468771211207330

Chen, C.A., Lee, M.H. \& Yang, Y.H. (2012). Branding Taiwan for Tourism using DEMATEL and ANP methods, The Service Industries Journal, 32(8), 1355-1373. http://dx.doi.org/10.1080/02642069.2010.545881

Chen, C.A., Lee, H.L., Lee, M.H. \& Yang, Y.H. (2011). How to Develop Taiwan's Tourism Nation Brand. African Journal of Business Management, 5(16), 6764-6773. http://dx.doi.org/ 10.5897/AJBM10.993

Chang, Y.Y., Su, W.C., \& Chang, C.Y. (2010). Correlation between Students' Performance in Horticultural Field Activities and Their Enhancement in Attention and Sense of Achievement. Journal of the Taiwan Society for Horticultural Science, 56(1), 57-65.

Chris H., \& Lindsay H. (1998). Online Interactions: Developing a Neglected Aspect of the Virtual Classroom. Education Technology, 38(4), 48-55.

$\mathrm{Fu}$, B.S. \& Wang, H.L. (2010). The Impact of Employee's Performance Evaluation on Employment Relations. Bulletin of Labour Research, 26, 91-146.

Hsu, W. K., Huang, H.H., \& Wang, C. W. (2004). Teachers involved in online teaching platform of the factors (p. 67-72). National Chiao Tung University, Hsinchu City.

Huang, C.Y., Shyu, Joseph Z., \& Tzeng, G.H. (2007). Reconfiguring the Innovation Policy Portfolios for Taiwan's SIP Mall Industry. Technovation, 27(12), 744-765. http://dx.doi.org/10.1016/j.technovation.2007.04.002

Kuo, S. Y. (1990). A Discriminant Analysis of Teacher Burnout Based on Teacher Stresses and Professional Attitudes. Bulletin of Educational Psychology, 23, 71-97.

Lee, Y. D. (1999). Retrospect and Prospect in Organizational Communication Studies. Web Journal of Chinese Management Review, 2(5), 121-131.

Li, C. W., \& Tzeng, G. H. (2009). Identification of a threshold value for the DEMATEL method using the maximum mean de-entropy algorithm to find critical services provided by a semiconductor intellectual property mall. Expert Systems with Applications, 36, 9891-9898. http://dx.doi.org/10.1016/j.eswa.2009.01.073

Liou, J.H., Tzeng, H.G., \& Chang, H.C. (2007). Airline Safety Measurement Using a Novel Hybrid Model. Journal of Air Transport Management, 13(4), 243-249. http://dx.doi.org/10.1016/j.jairtraman.2007.04.008

Shen, C. Y. (2007). Taiwan college teachers use the Internet learning platform of the present situation and problems. Integrated Higher Education Database System In Taiwan, 10, 18-28.

Teng, J. Y. (2002). Project evaluation: methods and applications. National Taiwan Ocean University, Taiwan.

Tsai,W. H., Chou,W.C., \& Lai,C.W. (2010). An Effective Evaluation Model and Improvement Analysis for National Parks Websites: A Case Study of Taiwan, Tourism Management, 36(6), 936-952. 
Tsai,W. H., Hsu, J. L., Chen, C. H., Lin, W. R. \& Chen, S. P. (2010). An Integrated Approach for Selecting Corporate Social Responsibility Programs and Costs Evaluation in the International Tourist Hotel, International Journal of Hospitality Management, 29(3), 385-396. http://dx.doi.org/10.1016/j.tourman.2010.01.016

Tsai, W. H. \& Hsu, W. (2010). A Novel Hybrid Model Based on DEMATEL and ANP for Selecting Cost of Quality Model Development, Total Quality Management \& Business Excellence, 21(4), 439-456. http://dx.doi.org/10.1080/14783361003606852

Tsai, W. H., Leu, J. D., Liu, J. Y., Lin, S. J., \& Shaw, M. J. (2010). A MCDM Approach for Sourcing Strategy Mix Decision in IT Projects, Expert Systems with Applications, 37(5), 3870-3886. http://dx.doi.org/10.1016/j.eswa.2009.11.031

Tzeng, G. H., Chiang, C. H., \& Li, C.W. (2007). Evaluating Intertwined Effects in E-learning Programs: A Novel Hybrid MCDM Model Based on Factor Analysis and DEMATEL, Expert Systems with Applications, 32(4), 1028-1044. http://dx.doi.org/10.1016/j.eswa.2006.02.004

Wu, J. P. \& Wu, H. Y. (2005). The Impacts of Group Characteristics and Size on Collaborative Learning under the Synchronous Discussion of a Distance Learning System. Journal of Information Management-Concepts, Systems, and Applications, 7(1), 55-76.

Yang, C. S. (2003). Web-based Interpreter Training: Interaction between the Physical and Virtual Classrooms. Studies of Translation and Interpretation, 8, 199-223.

Yu, M. Y. (2007). Research on the Influence of Staff's Performance Assessment and Leadership Style to Employee's Working Attitudes Take Merchandising Business of the Automobile as an Example. Thesis, Yuan Ze University, Taoyuan, Taiwan.

Table 1. The meaning of each criterion

\begin{tabular}{|c|c|c|}
\hline Dimension & Criterion & Comment \\
\hline \multicolumn{3}{|c|}{ A. Teacher's perception } \\
\hline a1 & $\begin{array}{l}\text { Acquire a sense of success from } \\
\text { web-based learning }\end{array}$ & $\begin{array}{l}\text { Teacher can feel the sense of success during } \\
\text { the course of web-based learning. }\end{array}$ \\
\hline a2 & Web-based learning is challenging. & Teacher is willing to try web-based learning. \\
\hline a3 & $\begin{array}{l}\text { Web-based learning is helpful to } \\
\text { students. }\end{array}$ & $\begin{array}{l}\text { Teacher understands that web-based learning } \\
\text { is helpful to students. }\end{array}$ \\
\hline \multicolumn{3}{|c|}{ B. School management measures } \\
\hline b1 & $\begin{array}{l}\text { The school's respect for the opinions of } \\
\text { teachers }\end{array}$ & $\begin{array}{l}\text { The school management unit respects the } \\
\text { opinions of teachers. }\end{array}$ \\
\hline b2 & $\begin{array}{l}\text { The school's overall communication } \\
\text { channels }\end{array}$ & $\begin{array}{l}\text { The school management unit fully } \\
\text { communicates with teachers about web-based } \\
\text { learning. }\end{array}$ \\
\hline b3 & $\begin{array}{l}\text { The school's fair and rational } \\
\text { performance evaluation system }\end{array}$ & $\begin{array}{l}\text { The school management unit provides fair } \\
\text { and effective evaluation criteria. }\end{array}$ \\
\hline \multicolumn{3}{|c|}{ C. Web-based learning system } \\
\hline c1 & Ease of use & Web-based learning system is easy to use. \\
\hline $\mathrm{c} 2$ & Usefulness & $\begin{array}{l}\text { Web-based learning system can increase the } \\
\text { teaching performance of teachers. }\end{array}$ \\
\hline $\mathrm{c} 3$ & Convenience & $\begin{array}{l}\text { The information of web-based learning } \\
\text { system is accessible. }\end{array}$ \\
\hline \multicolumn{3}{|c|}{ D. The interaction with learners } \\
\hline $\mathrm{d} 1$ & E-mail and group discussion & $\begin{array}{l}\text { Enhance the interaction with students via } \\
\text { E-mail and group discussion. }\end{array}$ \\
\hline $\mathrm{d} 2$ & Online conversation & $\begin{array}{l}\text { Respond to learners effectively and } \\
\text { immediately via online conversation. }\end{array}$ \\
\hline
\end{tabular}


Table 2. Total relation matrix of criteria

\begin{tabular}{llllllllllll}
\hline & $\mathrm{a} 1$ & $\mathrm{a} 2$ & $\mathrm{a} 3$ & $\mathrm{~b} 1$ & $\mathrm{~b} 2$ & $\mathrm{~b} 3$ & $\mathrm{c} 1$ & $\mathrm{c} 2$ & $\mathrm{c} 3$ & $\mathrm{~d} 1$ & $\mathrm{~d} 2$ \\
\hline $\mathrm{a} 1$ & 0.3063 & 0.3537 & 0.2950 & 0.2968 & 0.3136 & 0.2896 & 0.3601 & 0.3736 & 0.3813 & $\mathbf{0 . 4 3 3 5 *}$ & 0.3480 \\
$\mathrm{a} 2$ & 0.3690 & 0.2320 & 0.2680 & 0.2734 & 0.2822 & 0.2461 & 0.3276 & 0.3370 & 0.3439 & 0.3920 & 0.3031 \\
$\mathrm{a} 3$ & $\mathbf{0 . 4 3 1 0 *}$ & 0.3665 & 0.2558 & 0.3372 & 0.3437 & 0.3181 & 0.3893 & 0.4036 & 0.4045 & $\mathbf{0 . 4 7 4 8 *}$ & 0.3647 \\
\hline $\mathrm{b} 1$ & 0.3708 & 0.2995 & 0.2786 & 0.2182 & 0.3058 & 0.2874 & 0.3359 & 0.3455 & 0.3524 & 0.3950 & 0.3072 \\
b2 & 0.3608 & 0.2976 & 0.2698 & 0.3026 & 0.2214 & 0.2680 & 0.3258 & 0.3354 & 0.3385 & 0.3907 & 0.3010 \\
b3 & 0.3033 & 0.2487 & 0.2315 & 0.2651 & 0.2722 & 0.1749 & 0.2853 & 0.2904 & 0.2963 & 0.3437 & 0.2697 \\
\hline $\mathrm{c} 1$ & 0.3583 & 0.3041 & 0.2913 & 0.2685 & 0.2923 & 0.2477 & 0.2753 & 0.3634 & 0.3817 & $\mathbf{0 . 4 3 1 6 *}$ & 0.3391 \\
$\mathrm{c} 2$ & 0.3793 & 0.3229 & 0.3016 & 0.2831 & 0.3037 & 0.2726 & 0.3704 & 0.2940 & 0.3950 & $\mathbf{0 . 4 5 0 3 *}$ & 0.3510 \\
$\mathrm{c} 3$ & 0.3688 & 0.3108 & 0.2974 & 0.2673 & 0.2913 & 0.2501 & 0.3679 & 0.3701 & 0.2919 & $\mathbf{0 . 4 3 5 4 *}$ & 0.3421 \\
\hline $\mathrm{d} 1$ & $\mathbf{0 . 4 1 5 9 *}$ & 0.3409 & 0.3179 & 0.2993 & 0.3029 & 0.2815 & 0.3919 & 0.3984 & 0.4066 & 0.3567 & 0.3581 \\
$\mathrm{~d} 2$ & 0.3558 & 0.2927 & 0.2733 & 0.2568 & 0.2630 & 0.2442 & 0.3566 & 0.3584 & 0.3768 & $\mathbf{0 . 4 1 4 7 *}$ & 0.2493 \\
\hline
\end{tabular}

* indicates it is larger than the threshold value 0.4147

Table 3. Causal influence level summarized table of criteria

\begin{tabular}{lrrrl}
\hline Criterion & $D$ & $R$ & $D+R$ & \multicolumn{1}{c}{$D-R$} \\
\hline $\mathrm{a} 1$ & 3.7515 & 4.0193 & 7.7708 & -0.268 \\
$\mathrm{a} 2$ & 3.3743 & 3.3693 & 6.7437 & 0.005 \\
$\mathrm{a} 3$ & 4.0891 & 3.0802 & 7.1693 & 1.0089 \\
\hline $\mathrm{b} 1$ & 3.4963 & 3.0682 & 6.5646 & 0.4281 \\
$\mathrm{~b} 2$ & 3.4117 & 3.192 & 6.6037 & 0.2197 \\
$\mathrm{~b} 3$ & 2.981 & 2.8801 & 5.8611 & 0.101 \\
\hline $\mathrm{c} 1$ & 3.5532 & 3.7862 & 7.3394 & -0.233 \\
$\mathrm{c} 2$ & 3.724 & 3.8698 & 7.5938 & -0.146 \\
$\mathrm{c} 3$ & 3.5929 & 3.9688 & 7.5617 & -0.376 \\
\hline $\mathrm{d} 1$ & 3.8701 & 4.5185 & 8.3886 & -0.648 \\
$\mathrm{~d} 2$ & 3.4417 & 3.5334 & 6.9752 & -0.092 \\
\hline
\end{tabular}




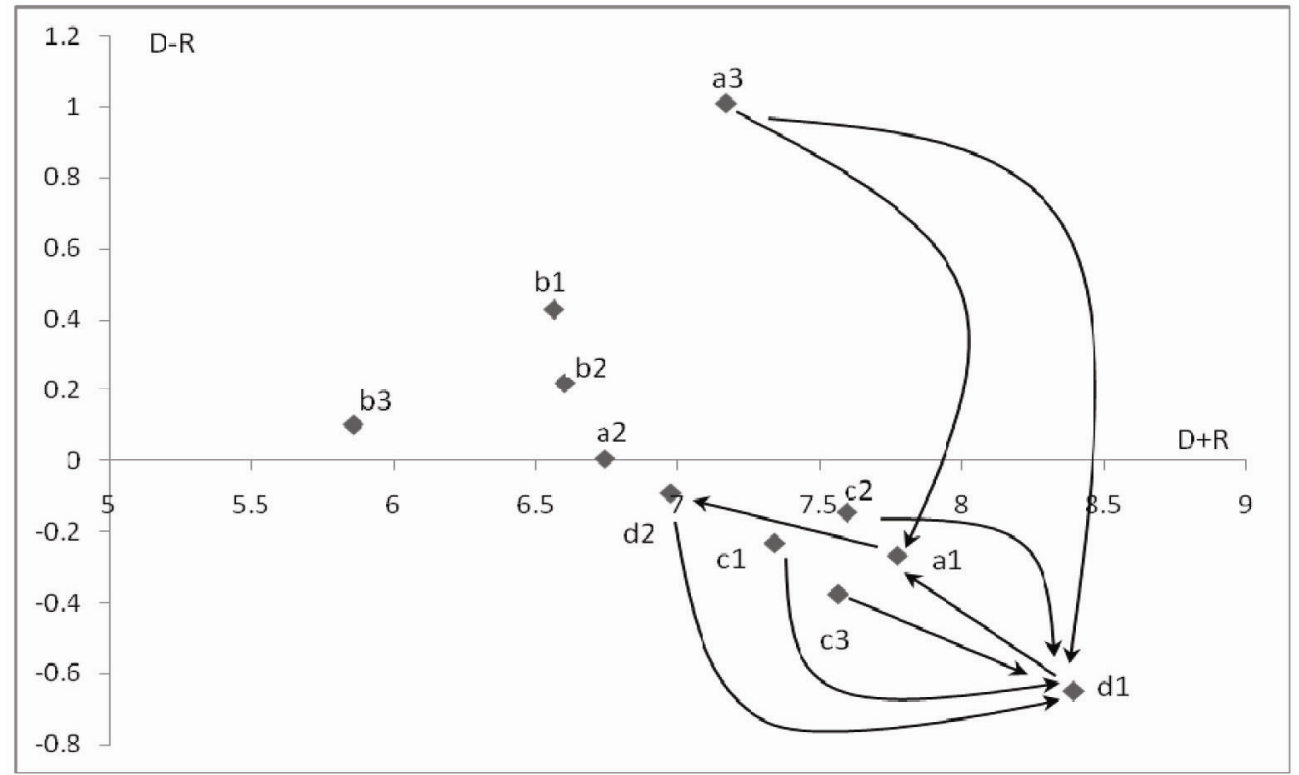

Figure 1. Causality diagram of criteria 